\title{
Pock Forming Unit
}

National Cancer Institute

\section{Source}

National Cancer Institute. Pock Forming Unit. NCI Thesaurus. Code C73576.

A measure of viable infectious entities (e.g. viral particles or group of particles) in the specimen or product defined as the smallest quantity of a viral suspension that can produce a cytopathic effect in the host chick chorio-allantoic membrane challeng ed with the defined inoculum, visible under the microscope and/or to the naked eye as a pock. 